\title{
Depression and Anxiety: Their Predictive Function for Weight Loss in Obese Individuals
}

\author{
Tanja Legenbauer $^{a} \quad$ Martina de Zwaan ${ }^{b} \quad$ Andrea Benecke $^{c} \quad$ Barbara Mühlhans $^{b}$ \\ Frank Petrak $^{\mathrm{a}}$ Stephan Herpertz ${ }^{\mathrm{a}}$ \\ ${ }^{a}$ Abteilung für Psychosomatische Medizin und Psychotherapie, LWL-Klinik Dortmund, \\ Universitätsklinikum der Ruhr-Universität Bochum, Dortmund, \\ ${ }^{b}$ Psychosomatische und Psychotherapeutische Abteilung, Universitätsklinikum Erlangen, \\ c Psychologisches Institut, Abteilung Klinische Psychologie und Psychotherapie, Johannes Gutenberg-Universität Mainz, Germany
}

\begin{abstract}
Key Words
Predictor variables on weight loss - Depression .

Anxiety · Binge eating - Weight loss treatment .

Obesity surgery
\end{abstract}

\section{Summary}

Objective: To investigate the impact of current mental disorders on weight loss with special consideration of depressive and/or anxiety disorders as well as binge eating behavior in obese individuals undergoing different weight loss treatments. Methods: Three different samples of obese individuals were investigated in a prospective, longitudinal study: participants in a conventional weight loss treatment program (CONV TREAT; $\mathrm{n}=250$ ), obesity surgery patients (OBES SURG; $n=153$ ), and obese control individuals (OC; $\mathrm{n}=128$ ). Current mental disorders and BMI were assessed at baseline and at 4-year follow-up. Results: OBES SURG patients with a depressive and/or anxiety disorder lost significantly less weight compared with those without a comorbid mental diagnosis. This result was not detected for CONV TREAT participants. A trend to gain weight was seen in $O C$ participants with a depressive and/or anxiety disorder, whereas OC participants without current mental disorders at baseline lost some weight. Binge eating behavior at baseline did not predict weight loss at 4-year followup. Conclusions: These results underline the importance of addressing current depressive and anxiety disorders in obese patients, especially when such patients are undergoing obesity surgery.

\section{Introduction}

Obesity is an increasingly prevalent public health problem, with approximately half the current US population being overweight or obese [1]. Although many studies have shown that obesity is associated with numerous medical complications [2], much less is known about its association with mental disorders. There is empirical evidence for a higher risk for mental disorders, in particular depression, anxiety, and eating disorders, in obese individuals who present for treatment as well as obese individuals in the general population [3-10]. However, whether comorbid mental disorders, especially depression, influence the short-term and long-term course of weight after treatment is a controversial issue [10-15].

A recent review of original studies published since 1995 showed that, when assessed before conventional weight loss treatment, depression does not predict treatment outcome [16]. However, the National Weight Control Registry, which provides information about the strategies used by obese individuals capable of achieving and maintaining long-term weight loss, indicated that low levels of depression are associated with long-term success [17]. Studies of the association of mental disorders, especially depression, with obesity surgery have yielded inconsistent results: some studies showed a positive association [18], whereas other investigations yielded a negative association $[19,20]$ between preoperative depression and weight loss [21].

Considerable evidence indicates that obesity and depression each may be related to binge eating (BE) behavior in general, as well as DSM-IV-defined binge eating disorder (BED) [14]. Moreover, clinical and community studies have found significantly higher rates of depression in obese persons with BE behavior compared with obese persons who do not

\begin{tabular}{ll}
\hline KARGER & @ 2009 S. Karger GmbH, Freiburg \\
Fax +497614520714 & Accessible online at: \\
Information@Karger.de & www.karger.com/ofa \\
www.karger.com &
\end{tabular}


Fig. 1. Patient flow over 4-year follow-up period. Presentation of number of participants excluded from the analysis; number of individuals with any mental disorder, depressive disorder, and anxiety disorder; and composition of the subsample with comorbid anxiety and/or depressive disorders for both assessment time points ( $\mathrm{T} 1$ and $\mathrm{T} 2)$.

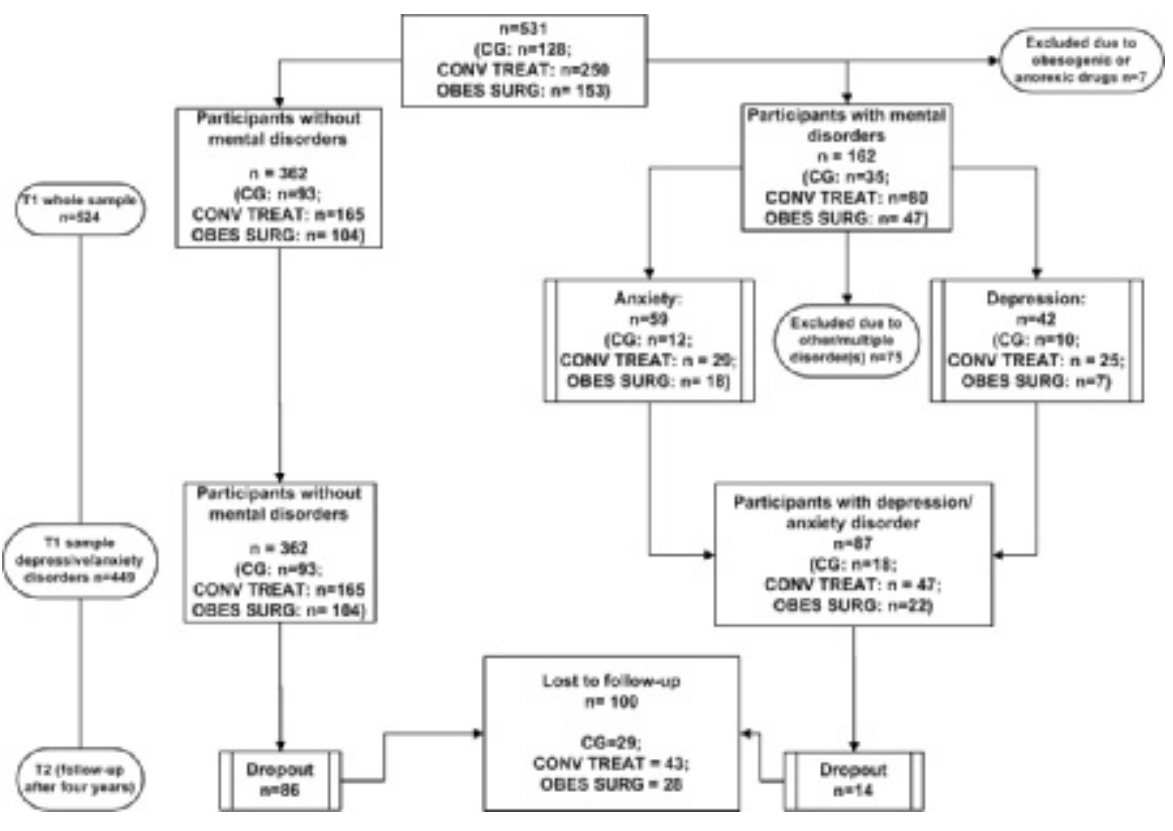

engage in BE [22, 23]. Indeed, it has been hypothesized that a potential relationship between obesity and depression is mediated via a shared relationship with BE [24-26].

Several studies have shown that besides depression or elevated scores on depressive symptoms, many obese individuals also reported higher scores for anxiety when self-report measures were administered $[9,15]$. In addition, both obese women $[7,27,28]$ and individuals of either sex seeking weight loss treatment seem to have higher rates of anxiety disorders $[4,29]$. Possible links between obesity and anxiety have been investigated less thoroughly compared with those between obesity and depression. Thus, the relationship between obesity and anxiety remains unclear [27, 30].

One shortcoming of the majority of studies is the use of self-report questionnaires instead of structured psychiatric interviews [27] to assess depressive or anxiety disorders [31, 32] as well as disturbed eating patterns $[15,33]$. Because questionnaires are less reliable than structured clinical interviews, this circumstance may be one reason for the lack of consistent information regarding the predictive value of depressive and/or anxiety disorders for weight loss.

In order to overcome these shortcomings, we investigated the predictive value of mental disorders in general and of depressive and/or anxiety disorders in particular on weight loss after conventional or bariatric surgery weight loss treatment. $\mathrm{BE}$ was considered as a possible moderator variable between mental disorders and weight loss. First, we hypothesized that obese individuals with current comorbid mental disorders, in particular depressive and/or anxiety disorders, who participate in conventional weight loss treatment program (CONV TREAT) or undergo obesity surgery (OBES SURG) lose less weight compared with obese individuals who do not have any current mental disorder. Second, we hypothesized that the negative effect on weight loss in obese individuals with current comorbid depression and anxiety is influenced by $\mathrm{BE}$ behavior. To our knowledge, this is the first study to examine the impact of current mental disorders, in particular depressive and anxiety disorders, on the course of weight after weight loss treatment and in a non-treatment-seeking population sample of obese adults.

\section{Material and Methods}

\section{Design and Procedure}

This multicenter, prospective study was designed to report on psychological, social, and genetic aspects of obesity and the course of weight after conventional weight loss treatment or bariatric surgery. Methodological details are given elsewhere [34]. Mental disorders and, in particular, depressive disorders (major depression and dysthymia) and anxiety disorders (agoraphobia, specific phobia, social phobia, panic disorder, and generalized anxiety disorder) were assessed at baseline through the use of structured psychiatric interviews (Composite International Diagnostic Interview; CIDI). $\mathrm{BE}$ behavior (bulimia nervosa, $\mathrm{BED}$, atypical binges ('grazing'), and eating disorder not otherwise specified (EDNOS) were assessed through the use of the Structured Interview for Anorexia and Bulimia Nervosa (SIAB). As a control group, we used a random sample of obese individuals from the general population who were not dieting or actively losing weight at the time of the investigation (OC). Exclusion criteria were age below 18 and above 65, a diagnosis of psychotic disorder or dementia, women who had given birth within the past year and were continuing to lactate, the use of drugs with known influence on weight, and difficulties understanding the German language.

CONV TREAT participants at four different obesity centers in the Ruhr area of Germany, an area with a total population of about 6 million people, were asked to join the study and were assessed before the start of our treatment program. Treatment strategies of the obesity centers were based predominantly on Optifast ${ }^{\circledast}$ programs, which offer a multidimensional therapy approach with weekly group sessions during a period of 1 year. OBES SURG patients in six surgery departments in Germany 
Table 1. Distribution of current mental disorders among treatment and control groups $^{\mathrm{a}}$

\begin{tabular}{|c|c|c|c|c|c|c|c|c|}
\hline & \multicolumn{2}{|c|}{$\begin{array}{l}\text { Total sample } \\
(\mathrm{n}=524)\end{array}$} & \multicolumn{2}{|c|}{$\begin{array}{l}\text { Control group } \\
(\mathrm{n}=128)\end{array}$} & \multicolumn{2}{|c|}{$\begin{array}{l}\text { Conventional } \\
\text { treatment } \\
(\mathrm{n}=245)\end{array}$} & \multicolumn{2}{|c|}{$\begin{array}{l}\text { Surgery } \\
(\mathrm{n}=151)\end{array}$} \\
\hline & $\mathrm{n}$ & $\%$ & $\mathrm{n}$ & $\%$ & $\mathrm{n}$ & $\%$ & $\mathrm{n}$ & $\%$ \\
\hline \multicolumn{9}{|l|}{ Any mental disorder } \\
\hline No & 362 & 69 & 93 & 72.7 & 165 & 67.3 & 104 & 68.8 \\
\hline Yes & 162 & 31 & 35 & 27.3 & 80 & 32.7 & 47 & 31.1 \\
\hline Depressive disorders* & 42 & 8 & 10 & 9.4 & 30 & 12.2 & 8 & 5.3 \\
\hline Anxiety disorders* & 59 & 11.3 & 12 & 7.8 & 29 & 11.8 & 18 & 11.9 \\
\hline BE behavior & 147 & 28.1 & 19 & 14.8 & 89 & 36.3 & 38 & 25.2 \\
\hline
\end{tabular}

${ }^{\mathrm{a}}$ Absolute numbers and percentage of the distribution of any mental disorder in relation to the factor absence/presence of mental disorders as well as frequency of depressive disorders, anxiety disorders, and binge eating behavior including grazing among the subgroups.

$* \mathrm{n}=14$ participants reported both depression and anxiety disorders and thus are included in both number of participants with depressive disorders and number of participants with anxiety disorders. were approached to join the study and were assessed on the same day they were admitted to the hospital. The OC was a population-based sample of obese men and women selected randomly from the mandatory residence list of the city of Essen (about 600,000 inhabitants), Federal State of Northrhine-Westphalia. The residence list is regarded as the most complete sampling frame for population-based studies in Germany [35] Individuals who were participating in a weight loss program or were on a diet at the time of the investigation were excluded from the OC [for more details see 34]. We certify that all applicable institutional and governmental regulations concerning the ethical use of human volunteers were followed during this research. The study protocol was approved by the Ethics Committee of the University of Essen. All participants gave written, informed consent.

\section{Participants}

A total of 531 individuals participated in the study: 250 CONV TREAT participants, 153 OBES SURG patients (exclusively gastric banding), and 128 obese individuals (OC). All participants were asked about current medication. Those who reported the use of anorexic or obesogenic drugs either at T1 or T2 were excluded due to the drugs' effects on the course of weight $(n=7 ; 13 \%)$. Seven participants who were taking anti-depressant medication in the form of serotonin re-uptake inhibitors (SSRI) were included in the analysis. Of the remaining 524 participants, $162(31 \%)$ suffered from a current mental disorder. Additional details about the distribution of mental disorders in the total sample are reported elsewhere [34]. In the second step of the analysis, only obese individuals with a current depressive and/or anxiety disorder and obese individuals without any current comorbid mental diagnosis were included. The total number of participants within this second set of analyses was 449 (85.6\%; OC: $\mathrm{n}=111$; CONV TREAT: $\mathrm{n}=212$; OBES SURG: $\mathrm{n}=126$ ) (fig. 1).

At the 4-year follow-up, 407 individuals of the initial sample (77.7\%) could be re-assessed. Those who dropped out did not differ significantly in age, BMI, gender, presence of BE behavior, or presence of any disorder other than anxiety/depression. However, there were significant differences between those who dropped out and those who remained in the study in relation to presence of mental disorders in general $\left(\chi^{2}(1)\right.$ $=4.398, \mathrm{p}=0.036)$ and presence of depressive/anxiety disorders $\left(\chi^{2}(1)\right.$ $=4.183, \mathrm{p}=0.041)$, with individuals who dropped out reporting fewer mental disorders in general and fewer depressive/anxiety disorders. The attrition rate of the subsample who reported no current mental disorder at baseline was $23.8 \%(\mathrm{n}=86)$; the attrition rate of the subsample who met the criteria for a depressive and/or anxiety disorder at baseline was
$14.6 \%(\mathrm{n}=14)$. The percentage of those with any other current mental disorder who were lost to follow-up was $27.4 \%(\mathrm{n}=17)$. The attrition rates did not differ significantly between the non-comorbid and comorbid samples.

\section{Instruments}

We used the fully standardized M-CIDI/DIA-X [36], to assess mental disorders (current and lifetime) including nicotine-related disorders according to the criteria of ICD-10 [37] and DSM-IV [38]. 'Current diagnosis' refers to symptoms reported for the past $2-4$ weeks. Reliability and percent validity of the M-CIDI/DIA-X have been confirmed in several investigations [39].

The short version of the SIAB-EX [40] was used to assess bulimia nervosa, BED, and EDNOS according to DSM-IV criteria. The SIABEX also permits the assessment of atypical binges ('grazing') defined as 'permanent eating' [41]. The SIAB is a highly structured interview with well-documented reliability and validity among patients with eating disorders [40]. Participants were interviewed by one of four trained clinical psychologists who were monitored throughout the study. Body weight and height were measured under controlled conditions after the removal of shoes and heavy clothing. The following diagnoses based on the SIAB were summarized under the term 'BE behavior': bulimia nervosa, BED, EDNOS (e.g., the criterion of a minimum of two binges per week was not met), and atypical binges ('grazing').

\section{Statistical Analysis}

Our analysis was controlled for the influence of gender because gender differences are associated with depression and obesity [e.g. 32]. Therefore, we performed a $\chi^{2}$-test to assess differences in the distribution of gender among the groups. By means of ANCOVA we investigated possible differences in relation to presence or absence of any current mental disorders. We entered gender as a covariate and the factors treatment and presence of mental illness as independent variables. BMI and age were entered as dependent variables. The same procedure was followed within the second data set (presence/absence of a current comorbid depressive and/or anxiety disorder; independent variable) in order to detect differences among the subsamples at baseline level. Taking into account that obese individuals with and without any current comorbid mental disorder and depressive/anxiety disorder, respectively, were distributed over the three subsamples with large differences in intial BMI, the design of the study covered only within intervention group analyses: we performed a stepwise hierarchical linear regression analysis separately for each intervention group, with reduction of BMI as a dependent variable. As pos- 
sible predictors, presence of current mental disorder at baseline and presence of depressive and/or anxiety disorder at baseline were entered in the first step. To control the influence of BE behavior on the association between mental diagnosis and weight loss (reduction in BMI), we entered $\mathrm{BE}$ behavior at the second step; lastly, to control the influence of gender, we entered this feature at the third step. Finally, we performed t-tests for independent samples to compare participants with and without a current comorbid depressive and/or anxiety disorder within each intervention group. In addition, we controlled the change of BMI over time within each subsample with paired t-tests in order to explain differences within the subsamples.

\section{Results}

\section{Sample Characteristics}

Based on the CIDI, 162 (30.9\%) individuals of the total sample reported a current comorbid mental disorder at baseline. Of these, 42 reported a depressive disorder $(25.9 \%)$ and 59 an anxiety disorder $(36.1 \%)$. As 14 participants reported both a depressive and an anxiety disorder, the subsample of individuals who reported a current depressive and/or anxiety disorder at baseline consisted of 87 participants. Within this subsample, 23 individuals (14.9\%) suffered from more than one disorder (e.g. depressive and/or anxiety disorder plus somatoform disorder or nicotine abuse). Bipolar disorders were not reported. In addition, $147(28.1 \%)$ of the total sample ( $\mathrm{n}=$ 524) reported $\mathrm{BE}$ behavior at baseline (table 1).

\section{Differences among the Samples at Baseline}

There was no difference between the treatment groups $\left(\chi^{2}(2)\right.$ $=1.246, \mathrm{p}=0.536)$ with regard to gender distribution. However, more female obese participants reported a current comorbid mental disorder compared with the male obese participants $\left(\chi^{2}(1)=14.016, \mathrm{p}<0.001\right)$. The same result was obtained when only depressive and/or anxiety disorders were included in the analysis $\left(\chi^{2}(1)=14.259, \mathrm{p}<0.001\right)$. OBES SURG patients had a significantly higher BMI compared with participants of CONV TREAT and obese individuals not dieting $\left(\mathrm{OC} ; \mathrm{F}(2,516)=147.904, \mathrm{p}<0.001, \eta^{2}=0.364\right)$ (table 2). Including only depressive/anxiety disorders in the ANCOVA, a similar result was found $(F(2,445)=95.275$, $\left.\mathrm{p}<0.001, \eta^{2}=0.296\right)$. Gender as a covariate was not of statistical significance in either analysis. In addition, OBES SURG patients were younger than participants of conventional weight loss treatment programs (CONV TREAT) and obese controls $\left(\mathrm{OC} ; \mathrm{F}(2,517)=5.235, \mathrm{p}=0.006, \eta^{2}=0.020\right)$; patients who reported a comorbid mental disorder were younger than those without mental disorders $(\mathrm{F}(1,517)=8.381, \mathrm{p}=0.004$, $\left.\eta^{2}=0.016\right)$. A comparison of participants who had a comorbid depressive/anxiety disorder with non-comorbid participants among the three subsamples revealed no difference between comorbid and non-comorbid participants in relation to age, but treatment groups differed significantly $(F(2,442)=4.008$, $\left.\mathrm{p}=0.019, \eta^{2}=0.018\right)$. 
Fig. 2. Course of BMI over time. Mean scores for BMI at $\mathrm{T} 1$ and $\mathrm{T} 2$ separated according to intervention groups as well as present psychiatric diagnosis vs. no comorbid psychiatric diagnosis $(\mathrm{OC} \mathrm{NO}=$ control probands with no comorbid psychiatric diagnosis; OC YES = control probands with a comorbid depressive/ anxiety disorder at T1; CONV TREAT NO $=$ participants of conventional treatment programs with no comorbid psychiatric diagnosis; CONV TREAT YES = participants of conventional treatment programs with a comorbid depressive/anxiety disorder at T1; OBES SURG $\mathrm{NO}=$ obese individuals undergoing obesity surgery (gastric banding) with no comorbid psychiatric diagnosis; OBES SURG YES = obese individuals undergoing obesity surgery (gastric banding) with comorbid depressive/ anxiety disorder at $\mathrm{T} 1$ ).

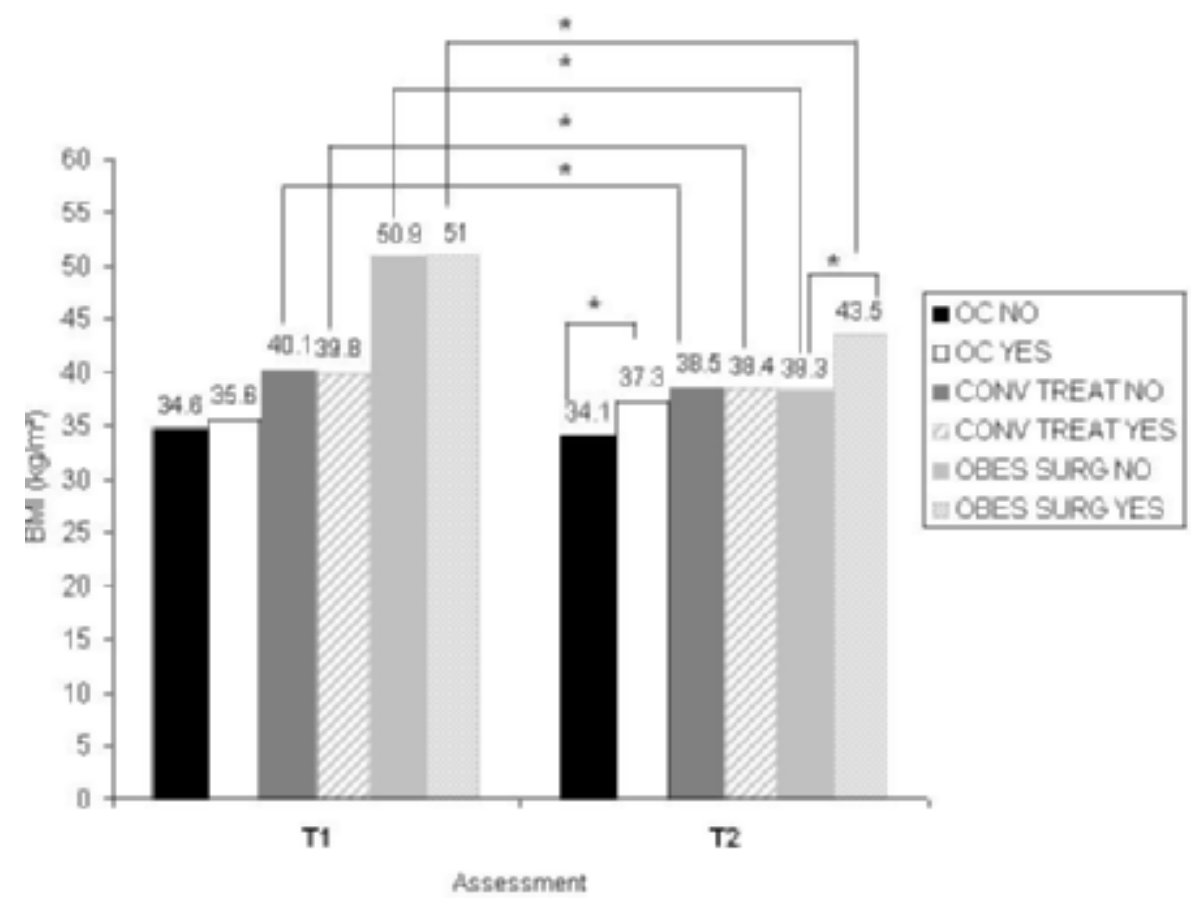

\section{Predictive Value of a Comorbid Current Baseline Diagnosis} on Weight Loss

Stepwise linear regression analysis with presence of comorbid depressive and/or anxiety disorder, presence of any mental disorder, and number of comorbid disorders as independent variables revealed that the presence or absence of a current comorbid depressive and/or anxiety disorder had a statistically significant impact on weight loss among both OBES SURG patients $(\mathrm{B}=-4.891, \beta=-0.201, \mathrm{p}=0.049)$ and OC individuals $(\mathrm{B}=-2.106, \beta=-0.259, \mathrm{p}=0.010)$, but not among CONV TREAT participants. A current comorbid depressive and/or anxiety disorder at baseline explained about $4.0 \%$ and $6.7 \%$ of the variance of weight loss (BMI) in OBES SURG patients and OC individuals, respectively. Neither the presence of a current comorbid disorder nor of BE behavior had a significant influence on the amount of weight loss in any of the obese groups.

In order to further investigate the influence of the presence/absence of depressive and/or anxiety disorders on the course of weight in the treatment subsamples, we performed post-hoc t-tests comparing participants who had a comorbid depressive and/or anxiety disorder with participants who did not have any current comorbid disorder at baseline within each treatment subsample. OBES SURG patients exhibited a significant weight loss; however, OBES SURG patients who had a current comorbid depressive and/or anxiety disorder lost significantly less weight compared with OBES SURG patients who did not have any current comorbid mental disorder at baseline. In the CONV TREAT group, no significant difference in weight loss could be detected between comorbid and non-comorbid participants. Obese controls suffering from a current depressive and/or anxiety disorder at baseline showed a trend toward gaining weight, whereas non-comorbid controls did not lose weight. Similar to the OBES SURG patients, a current comorbid depressive and/or anxiety disorder at baseline in OC individuals led to a poorer outcome regarding weight loss compared with non-comorbid controls during follow-up (fig. 2, table 3).

Taken together, obesity plus a current comorbid depressive and/or anxiety disorder seem to influence the course of weight negatively in both obese individuals without weight loss intervention (OC) and OBES SURG patients. However, no effect could be detected in individuals participating in CONV TREAT.

\section{Discussion}

The aim of this study was to investigate the predictive value of current comorbid mental disorders in general and depressive and/or anxiety disorders in particular on the course of weight among obese individuals in three different samples: participants in a conventional treatment program, obesity surgery patients, and obese controls. In addition, BE behavior was examined as a possible moderator between depression/anxiety and obesity.

Four main results were obtained:

i) In contrast to baseline current psychiatric comorbidity in general, baseline current depressive and/or anxiety disorders exhibited a significant influence on the course of weight in certain individuals.

ii) Patients who were undergoing obesity surgery and suffered from a comorbid depressive/anxiety disorder at baseline 
Table 3. Mean BMI scores and BMI differences as well as test statistics across the subsamples ${ }^{\mathrm{a}}$

\begin{tabular}{|c|c|c|c|c|c|c|}
\hline & \multicolumn{6}{|l|}{ Comorbidity } \\
\hline & \multicolumn{2}{|c|}{ control group $(\mathrm{n}=128)$} & \multicolumn{2}{|c|}{ conventional treatment $(\mathrm{n}=245)$} & \multicolumn{2}{|c|}{ surgery $(n=151)$} \\
\hline \multicolumn{7}{|l|}{ BMI } \\
\hline $\mathrm{T} 1$ & $35.1 \pm 4.7$ & $35.8 \pm 6.0$ & $40.9 \pm 7.0$ & $39.6 \pm 7.2$ & $50.4 \pm 7.9$ & $51.8 \pm 5.2$ \\
\hline $\mathrm{T} 2$ & $33.9 \pm 4.4$ & $37.6 \pm 8.6$ & $38.4 \pm 8.3$ & $38.4 \pm 7.8$ & $38.3 \pm 7.0$ & 43.96 .4 \\
\hline Paired t-tests & $\begin{array}{l}t(70)=1.433 \\
p=0.156\end{array}$ & $\begin{array}{l}\mathrm{t}(15)=-1.791 \\
\mathrm{p}=0.093\end{array}$ & $\begin{array}{l}\mathrm{t}(102)=2.952 \\
\mathrm{p}=0.004\end{array}$ & $\begin{array}{l}\mathrm{t}(30)=1.942 \\
\mathrm{p}=0.062\end{array}$ & $\begin{array}{l}\mathrm{t}(67)=14.228 \\
\mathrm{p}<0.001\end{array}$ & $\begin{array}{l}\mathrm{t}(10)=4.879 \\
\mathrm{p}=0.001\end{array}$ \\
\hline \multicolumn{7}{|l|}{ BMI (diff) } \\
\hline $\mathrm{T} 1-\mathrm{T} 2$ & $0.46 \pm 2.7$ & $-1.8 \pm 4.0$ & $1.6 \pm 45.4$ & $1.2 \pm 3.5$ & $12.5 \pm 7.3$ & $7.9 \pm 5.3$ \\
\hline Indirect t-tests & \multicolumn{2}{|c|}{$\mathrm{t}(85)=2.737 ; \mathrm{p}=0.008$} & \multicolumn{2}{|c|}{$\mathrm{t}(132)=0.333 ; \mathrm{p}=0.739$} & \multicolumn{2}{|c|}{$\mathrm{t}(77)=2.015 ; \mathrm{p}=0.047$} \\
\hline
\end{tabular}

${ }^{a}$ Mean scores for BMI at baseline (T1) and 4 years later (T2) and BMI difference (T1 - T2) separated according to intervention groups as well as presence of depressive/anxiety disorders. In addition, test statistics between comorbid and non-comorbid groups ( $\mathrm{t}$-tests for independent samples) and paired t-tests for changes within the follow-up period within each sample are provided.

lost significantly less weight during the follow-up period of 4 years compared with mentally healthy patients.

iii) Compared with participants who did not have a current mental disorder at baseline, comorbid obese individuals showed, on the whole, a nonsignificant trend toward weight gain; however, obese controls, whether or not they were diagnosed with a comorbid depressive and/or anxiety disorder, did not show a significant change in weight over the 4-year period. Nevertheless, the difference in weight changes between the comorbid and non-comorbid obese controls was significant.

iv) Participants of a conventional treatment program showed a significant weight loss during follow-up that was independent of a comorbid depressive and/or anxiety disorder at baseline.

Our hypothesis was confirmed regarding the presence of specific comorbid disorders (depressive/anxiety disorders) at baseline, but the presence of any mental disorder demonstrated no influence on the course of weight after weight reduction programs. Moreover, this association of comorbid depressive/ anxiety disorders with course of weight was seen especially in OBES SURG patients, but no impact of depressive/anxiety disorders on the course of changes in weight could be detected in individuals taking part in CONV TREAT. Furthermore, general psychiatric comorbidity and depressive/anxiety disorders in particular influenced the course of weight in untreated obese controls.

Several issues have to be discussed in connection with our results. First, depressive disorders often result in an unhealthy lifestyle, with both high-calorie eating behavior and little physical activity known to be associated with rapid regaining of weight $[17,42]$. A similar phenomenon may be true for anxiety disorders, in particular social phobia, agoraphobia, and panic disorder, all known to be associated with increasing social isolation and less physical activity. Second, the adoption of exercise, improvements in body image (e.g. following some initial weight loss), and regular social contact with a supportive group [43] and the intervention team are some factors that are likely to improve mood and psychological adjustment during weight loss. As Teixeira and colleagues [16] pointed out, improvements in depressive symptoms during weight loss treatment may occur [see also 44] and co-vary with weight changes [28]. We assume that, especially in the case of obesity grade 3 , biological counterregulatory mechanisms toward weight loss $[16,45]$ can hardly be controlled by motivational factors and behavioral strategies that may be influenced by psychopathology and mental disorders. Thus, although voluntary changes in behavior often can effect short-term weight change, the available scientific evidence suggests that over the long term the neural centers that control appetite overcome these motivational factors; regardless of a comorbid mental disorder and weight loss treatment strategies consisting of nutrition rehabilitation, behavior therapy, and physical activity, the lost weight is regained [46]. Only by means of a surgical intervention can these powerful biological counterregulatory mechanisms be disabled [47], and the influence of psychological variables such as depression and anxiety on feeding behavior or physical activity, for example, become apparent.

On the other hand, the lack of a difference in BMI reduction between comorbid and non-comorbid obese individuals in CONV TREAT might be due to the fact that because of the therapeutic setting depressive and anxiety symptoms were reduced and, thus, weight was lost to a similar degree in both subsamples. Previous research findings support this alternative interpretation by providing evidence of weight loss/mood elevation associations among obese individuals in weight loss treatment programs [48]. Thus, it might be worthwhile to further examine the effects of cognitive behavioral treatment 
components in weight loss therapy regarding the enhancement of weight loss by decreasing depressive and anxiety symptoms [see also 12].

BE behavior had no predictive value for the course of changes in weight after CONV TREAT or OBES SURG. These results are surprising, given the evidence that obese individuals who engage in $\mathrm{BE}$ consume more calories, a greater percentage of calories as fat, and a lesser percentage as protein than do individuals who do not engage in BE [26]. Furthermore, binge eaters report significantly more maladaptive diet-related behaviors than non-binge eaters and regain significantly more weight, at least after conventional weight loss treatment [49]. Consequently, previous evidence indicates that $\mathrm{BE}$ behavior should be considered a negative prognostic indicator in obesity $[50,51]$. However, this recommendation has been questioned in recent years [50-54], especially with regard to bariatric surgery; numerous studies point out that the redevelopment of BE behavior post surgery, rather than $\mathrm{BE}$ prior to obesity surgery, predicts weight loss [10, 21, 55-57].

Our study has several limitations that need to be addressed. One limitation is that the samples of the comorbid patients who suffered from either a current depressive or anxiety disorder were rather small; therefore, the impact of a single current mental disorder on the course of changes in weight could not be analyzed separately. Future studies should use larger samples to investigate these current mental disorders separately; it is possible that current depression alone or current anxiety alone may explain most of the variance of weight loss after treatment [58].

The non-randomized sample selection of the CONV TREAT participants and the OBES SURG patients also has to be mentioned. Furthermore, lifetime diagnoses should also be considered in future studies to investigate long-term changes in weight in obese individuals. About $48 \%$ of the participants in CONV TREAT had a BMI of more than $40 \mathrm{~kg} / \mathrm{m}^{2}$. For these participants, the more appropriate treatment would have been obesity surgery [59]. Thus, we do not know whether our results can be replicated for less obese individuals. Another possible limitation might be that those who dropped out reported fewer mental disorders in general and fewer depressive/anxiety disorders in particular compared with those who remained in the study. This circumstance might bias the re- sults and needs further consideration in future studies. Finally, we did not distinguish ordinary depression from atypical depression [60], which has been shown to differ from ordinary depression by the presence, among other things, of either increased appetite or weight gain. Studying primarily nonclinical psychiatric samples, we assume that the number of severe cases of depression with melancholic symptoms, for example, and weight loss was minimal. In order to shed more light on the rather divergent findings regarding an association between BMI and depressive symptoms, it might be worthwhile to differentiate these types of depression when attempting to link them with obesity and weight loss treatment.

In conclusion, the results of this study suggest that, for obese patients who are undergoing bariatric surgery or attending conventional weight reduction programs, the identification of psychopathological predisposing factors to poorer treatment outcomes could help in the optimization of interventions; such interventions may lead to improved treatment outcomes in the diverse subgroups, e.g. those with and without comorbid depressive/anxiety disorders.

\section{Acknowledgements}

This work was supported by the Deutsche Forschungsgemeinschaft (German Research Council, DFG; He2665/2-1, He2665/2-2); the Bundesministerium für Bildung und Forschung (Federal Ministry of Education and Research; BMBF; 01GI0836); the Institute Danone for Nutrition, Munich, Germany; and the Deutsche Krankenversicherung (DKV). The authors wish to thank U. Machleit and Dr. T. Hulisz, Obesity Center Bochum an der Augusta-Kranken-Anstalt, Bochum; Prof. Dr. R. Weiner, Department of Surgery, Krankenhaus Sachsenhausen, Frankfurt; Dr. C. Stroh, Department of Surgery, Municipal Hospital, Gera; Dr. B. Kortner, Department of Surgery, St. Joseph Hospital, Oberhausen; Dr. T. Berg, Department of Surgery, Klinikum der Stadt Ludwigshafen am Rhein; and Prof. Dr. M. Kemen, Department of Surgery, Evangelisches Krankenhaus Herne.

\section{Disclosure}

S. Herpertz reports that he has received honorarium for travel support from Lilly, Lundbeck, Pfizer, Sanofi-Aventis. F. Petrak has received honoraria and grant/research support from Pfizer, Berlin-Chemie, Lilly, Novo Nordisk Pharma. T. Legenbauer, M. de Zwaan und B. Mühlhans report no conflict of interest.

\section{References}

1 National Institutes of Health: Clinical guidelines on the identification, evaluation, and treatment of overweight and obesity in adults: the evidence report. Obes Res 1998;6(suppl):51-209.

${ }_{2}$ Yang D, Fontaine KR, Wang C, Allison DB: Weight loss causes increased mortality. Obes Rev 2003;4:9-16.

3 Baumeister H, Härter M: Mental disorders in patients with obesity in comparison with healthy probands. Int J Obes 2007;31:1155-1164.
4 Britz B, Siegfried W, Ziegler A, Lamertz C, Herpertz-Dahlmann BM, Remschmidt H, Wittchen $\mathrm{HU}$, Hebebrand J: Rates of psychiatric disorders in a clinical study group of adolescents with extreme obesity and in obese adolescents ascertained via a population based study. Int $\mathbf{J}$ Obes Relat Metab Disord 2000;24:1707-1714.

5 Guerdjikova AI, McElroy SL, Kotwal R, Keck PEJ: Comparison of obese men and women with binge eating disorder seeking weight management. Eat Weight Disord 2007;12:19-23.
6 Heo M, Pietrobelli A, Fontaine KR, Sirey JA, Faity MS: Depressive mood and obesity in US adults: comparison and moderation by sex, gender, age and race. Int J Obes 2006;30:513-519.

7 Jorm AF, Korten AE, Christensen H, Jacomb PA, Rodgers B, Parslow RA: Association of obesity with anxiety, depression and emotional well-being: a community survey. Aust N Z J Public Health 2003; 27:434-440. 
8 Simon GE, von Korff M, Saunders K, Miglioretti DL, Crane PK, van Belle G, Kessler RC: Association between obesity and psychiatric disorders in the US adult population. Arch Gen Psychiatry 2006; 63:824-830.

$\checkmark 9$ Sullivan M, Karlsson J, Sjostrom L, Backman L, Bengtsson C, Bouchard C, Dahlgren S, Jonsson E, Larsson B, Lindstedt S, et al: Swedish Obese Subjects (SOS) - an intervention study of obesity. Baseline evaluation of health and psychosocial functioning in the first 1743 subjects examined. Int J Obes Relat Metab Disord 1993;17:503-512.

10 Wadden TA, Butryn ML, Sarwer DB, Fabricatore AN, Crerand CE, Lipschutz PE, Faulconbridge L, Raper S, Williams NN: Comparison of psychosocial status in treatment-seeking women with class III vs class I-II obesity. Surg Obes Relat Disord 2006;2: 138-145.

11 Berman WH, Raynes-Berman E, Heymesfield S, Fauci M, Ackerman S: The incidence and comorbidity of psychiatric disorders in obesity. J Personal Disord 1992;6:168-175.

12 De Panfilis C, Cero S, Dall'Aglio E, Salvatore P, Torre M, Maggini C: Psychopathological predictors of compliance and outcome in weight-loss obesity treatment. Acta Biomed 2007;78:22-28.

13 Goldsmith SJ, Anger-Friedfeld K, Beren S, Rudolph D, Boeck M, Aronne L: Psychiatric illness in patients presenting for obesity treatment. Int J Eat Disord 1992;12:63-71.

14 McElroy SL, Kotwal R, Malhotra S, Nelson EB, Keck PE, Nemeroff CB: Are mood disorders and obesity related? A review for the mental health professional. J Clin Psychiatry 2004;65:634-651.

15 Tuthill A, Slawik H, O'Rahilly S, Finer N: Psychiatric co-morbidities in patients attending specialis obesity services in the UK. QJM 2006;99:317-325.

16 Teixeira PJ, Going SB, Sardinha LB, Lohman TG: A review of psychosocial pre-treatment predictors of weight control. Obes Rev 2005;6:43-65.

17 Wing RR, Phelan S: Long-term weight loss maintenance. Am J Clin Nutr 2005;82(suppl 1):222-225.

-18 Averbukh Y, Heshka S, El-Shoreya H, Flancbaum L, Geliebter A, Kamel S, Pi-Sunyer FX, Laferrère B: Depression score predicts weight loss following Roux-en-Y gastric bypass. Obes Surg 2003;13:833836.

19 Hafner RJ, Watts JM, Rogers J: Quality of life after gastric bypass for morbid obesity. Int J Obes 1991;15:555-560.

20 Kinzl JF, Schrattenecker M, Traweger C, Mattesich M, Fiala M, Biebl W: Psychosocial predictors of weight loss after bariatric surgery. Obes Surg 2006; 16:1609-1614.

21 Herpertz S, Kielmann R, Wolf AM, Hebebrand J, Senf W: Do psychosocial variables predict weight loss or mental health after obesity surgery? - a systematic review. Obes Res 2004;12:1554-1569.

22 Specker S, de Zwaan M, Raymond N, Mitchell J: Psychopathology in subgroups of obese women with and without binge eating disorder. Compr Psychiatry 1994;35:185-190.

23 Yanovski SZ, Nelson JE, Dubbert BK, Spitzer RL: Association of binge eating disorder and psychiatric comorbidity in obese subjects. Am J Psychiatry 1993;150:1472-1479.

24 Devlin MJ, Goldfein JA, Dobrow I: What is this thing called BED? Current status of binge eating disorder nosology. Int J Eat Disord 2003;34(suppl): S2-S18.

25 Faith MS, Matz PE, Jorge MA: Obesity-depression associations in the population. J Psychosom Res 2002; 53:935-942.
26 Yanovski S, Leet M, Yanovski JA, Flood M, Gold PW, Kissileff HR, Walsh BT: Food selection and intake of obese women with binge eating disorder. Am J Clin Nutr 1992;56:975-980.

27 Becker ES, Margraf J, Türke V, Soeder U, Neumer $\mathrm{S}$ : Obesity and mental illness in a representative sample of young women. Int J Obes 2001;25(suppl 1): $55-59$.

28 Wadden TA, Steen SN, Wingate BJ, Foster GD: Psychosocial consequences of weight reduction: how much weight loss is enough? Am J Clin Nutr 1996; 63(suppl 3):461-465.

29 Black DW, Goldstein RB and Mason EE: Prevalence of mental disorder in 88 morbidly obese bariatric clinic patients. Am J Psychiatry 1992;149:227234.

30 Goldstein LT, Goldsmith SJ, Anger K, Leon AC: Psychiatric symptoms in clients presenting for commercial weight reduction treatment. Int J Eat Disord 1996;20:191-197.

31 Lang T, Hauser R, Schlumpf R, Klaghofer R, Buddeberg C: Psychological comorbidity and quality of life of patients with morbid obesity and requesting gastric banding. Schweiz Med Wochenschr 2000;130: 739-748.

32 Mamplekou E, Komesidou V, Bissias C, Papakonstantinou A, Melissas J: Psychological condition and quality of life in patients with morbid obesity before and after surgical weight loss. Obes Surg 2005; 15:1177-1184.

33 Nickel C, Widermann C, Harms D, Leiberich PL, Tritt K, Kettler C, Lahmann C, Rother WK, Loew TH, Nickel MK: Patients with extreme obesity: change in mental symptoms three years after gastric banding. Int J Psychiatry Med 2005;35:109-122.

34 Herpertz S, Burgmer R, Stang A, de Zwaan M, Wolf AM, Chen-Stute A, Hulisz T, Jöckel KH, Senf W: Prevalence of mental disorders in normal-weight and obese individuals with and without weight loss treatment in a German urban population. J Psychosom Res 2006;61:95-103.

35 Stang A, Ahrens W, Jöckel KH: Control response proportions in population-based case-control studies in Germany. Epidemiology 1999;10:181-183.

36 Wittchen HU: Reliability and validity studies of the WHO-Composite International Diagnostic Interview (CIDI): a critical review. J Psychiatr Res 1994; 28:57-84.

37 Dilling H: Internationale Klassifikation psychischer Störungen ICD-10.. Bern, Huber, 1994.

38 American Psychiatric Association: Diagnostic and Statistical Manual of Mental Disorders (DSM-IV). Washington DC, American Psychiatric Association, 1994

39 Wittchen H-U, Lachner G, Wunderlich U, Pfister $\mathrm{H}$ : Test-retest reliability of the computerized DSMIV version of the Munich-Composite International Diagnostic Interview (M-CIDI). Soc Psychiatry Psychiatr Epidemiology 1998;33:568-578.

40 Fichter M, Herpertz S, Quadflieg N, HerpertzDahlmann B: Structured Interview for Anorexic and Bulimic Disorders SIAB-EX for DSM-IV and ICD-10: updated (3rd) revision. Int J Eat Disord 1998;24:227-249.

41 Marcus MD, Smith D, Santelli R, Kaye W: Characterization of eating disordered behavior in obese binge eaters. Int J Eat Disord 1992;12:249-256.

42 Wing RR, Hill JO: Successful weight loss maintenance. Annu Rev Nutr 2001;21:323-341.
3 Renjilian DA, Perri MG, Nezu AM, McKelvey WF, Shermer RL, Anton SD: Individual versus group therapy for obesity: effects of matching participants to their treatment preferences. J Consult Clin Psychol 2001;69:717-721.

44 Rapoport L, Clark M, Wardle J: Evaluation of a modified cognitive-behavioural program for weight management. Int J Obes Relat Metab Disord 2000;24: 1726-1737.

45 Morton GJ, Cummings DE, Baskin DG, Barsh GS, Schwartz MW: Central nervous system control of food intake and body weight. Nature 2006;443:289295.

46 Friedman JM: Modern science versus the stigma of obesity. Nat Med 2004;10:563-569.

47 Cummings DE, Weigle DS, Frayo RS, Breen PA, Ma MK, Dellinger EP, Purnell JQ: Plasma ghrelin levels after diet-induced weight loss or gastric bypass surgery. N Engl J Med 2002;346:1622-1630.

48 Cuntz U, Leibbrand R, Ehrig C, Shaw R, Fichter MM: Predictors of post-treatment weight reduction after in-patient behavioral therapy. Int J Obes 2001; 25(suppl 1):S99-S101.

49 Marcus MD, Wing RR, Hopkins J: Obese binge eater: affect, cognitions, and response to behavioural weight control. J Consult Clin Psychol 1998; 56:433-439.

50 Kaplan AS, Ciliska D: The relationship between eating disorders and obesity: psychopathologic and treatment considerations. Psychiatr Ann 1999;29: 197-202.

51 Telch CF, Agras WS: Obesity, binge eating and psychopathology: are they related? Int J Eat Disord 1994;15:53-61.

52 Nauta H, Hospers H, Kok G, Jansen A: A comparison between a cognitive and a behavioral treatment for obese binge eaters and obese non-binge eaters. Behav Ther 2000;31:441-461.

53 Stunkard AJ, Allison KC: Binge eating disorder: disorder or marker? Int J Eat Disord 2003;34:107116.

54 Wilfley DE, Welch RR, Stein RI, Spurrell EB, Cohen LR, Saelens BE, Dounchis JZ, Frank MA, Wiseman CV, Matt GE: A randomized comparison of group cognitive behavior therapy and group interpersonal psychotherapy for the treatment of overweight individuals with binge eating disorders. Arch Gen Psychiatry 2002;59:713-721.

55 Burgmer R, Grigutsch K, Zipfel S, Wolf AM, de Zwaan M, Husemann B, Albus C, Senf W, Herpertz $\mathrm{S}$ : The influence of eating behavior and eating pathology on weight loss after gastric restriction operations. Obes Surg 2005;15:684-691.

56 Burgmer R, Petersen I, Burgmer M, de Zwaan M, Wolf AM, Herpertz S: Psychological outcome two years after restrictive bariatric surgery. Obes Surg 2007; 17:785-791.

57 de Zwaan M: Weight and eating changes after bariatric surgery: in de Zwaan M, Mitchell JE (eds) Bariatric Surgery: A Guide for Mental Health Professionals. New York, Routledge, Taylor and Francis Group, 2005, pp 77-99.

58 Hafner RJ, Rogers J, Watts JM: Psychological status before and after gastric restriction as predictors of weight loss in the morbidly obese. J Psychosom Res 1990;34(3):295-302.

59 NIH Conference. Gastrointestinal surgery for severe obesity. Consensus Development Conference Panel. Ann Intern Med 1991;115:956-961.

60 Matza LS, Revicki DA, Davidson JR, Stewart JW: Depression with atypical features in the National Comorbidity Survey. Arch Gen Psychiatry 2003;60: 817-826. 